Article

\title{
Immobilization of Genetically-Modified D-Amino Acid Oxidase and Catalase on Carbon Nanotubes to Improve the Catalytic Efficiency
}

\author{
Rong Li ${ }^{1}$, Jian Sun ${ }^{1}$, Yaqi Fu ${ }^{1}$, Kun Du ${ }^{1}$, Mengsha Cai ${ }^{2}$, Peijun $\mathrm{Ji}^{2, *}$ and Wei Feng ${ }^{1, *}$ \\ 1 Department of Biochemical Engineering, Beijing University of Chemical Technology, Beijing 100029, China; \\ 15117964965@163.com (R.L.), sunjian612@163.com (J.S.), nazume731@126.com (Y.F.), \\ 15210694831@126.com (K.D.) \\ 2 Department of Chemical Engineering, Beijing University of Chemical Technology, Beijing 100029, China; \\ li_fu420@163.com (M.C.) \\ * Correspondence: jipj@mail.buct.edu.cn (P.J.), fengwei@mail.buct.edu.cn (W.F.); Tel.: +86-010-6442-3254 (P.J.); \\ +86-010-6444-6249 (W.F.)
}

Academic Editor: David D. Boehr

Received: 24 March 2016; Accepted: 28 April 2016; Published: 9 May 2016

\begin{abstract}
D-amino acid oxidase (DAAO) and catalase (CAT) have been genetically modified by fusing them to an elastin-like polypeptide (ELP). ELP-DAAO and ELP-CAT have been separately immobilized on multi-walled carbon nanotubes (MWNTs). It has been found that the secondary structures of the enzymes have been preserved. ELP-DAAO catalyzed the oxidative deamination of D-alanine, and $\mathrm{H}_{2} \mathrm{O}_{2}$ was evolved continuously. When the MWNT-supported enzymes were used together, the generated hydrogen peroxide of ELP-DAAO could be decomposed in situ. The catalytic efficiency of the two immobilized enzymes was more than five times greater than that of free ELP-DAAO when the ratio of immobilized ELP-CAT to immobilized ELP-DAAO was larger than 1:1.
\end{abstract}

Keywords: D-amino acids oxidase; catalase; elastin-like polypeptide; immobilization; carbon nanotubes

\section{Introduction}

D-Amino acid oxidases (DAAOs) are flavoenzymes. They are technologically useful and have been studied as biocatalysts in industrial applications [1-4]. DAAOs are the key enzymes in the process converting cephalosporin $\mathrm{C}$ to 7-aminocephalosporanic acid (7ADCA), which is the important intermediate for semisynthetic cephalosporin antibiotics [5]. It has been proposed that evolved $\mathrm{H}_{2} \mathrm{O}_{2}$ is eliminated during the production of 7ADCA [6]. DAAOs can also be used to catalyze the production of $\alpha$-keto acids from essential D-amino acids [7,8], resolution of racemic mixtures of amino acids [9], and quantification of the D-amino acid content in biological fluids [10-15]. Cooperating with other enzymes, DAAOs promote the catalysis processes [16,17]. Under DAAOs catalysis, L-amino acids are obtained; they are key intermediates for the synthesis of pharmaceuticals [18].

D-Amino acid oxidases catalyze the conversion of D-amino acids into $\alpha$-keto acids, $\mathrm{H}_{2} \mathrm{O}_{2}$, and $\mathrm{NH}_{3}$. However, the accumulation of hydrogen peroxide can induce DAAO deterioration $[19,20]$. Moreover, the evolved hydrogen peroxide exhibits a by-product inhibitory effect on the conversion of substrates. It is indicated that the presence of hydrogen peroxide can reduce the catalytic efficiency of DAAOs [21]. To remove hydrogen peroxide, DAAO catalysis has been used together with catalase and horseradish peroxidase [22-24], and catalase was co-immobilized with DAAOs on a support $[8,9,25,26]$.

In previous work, D-amino acids oxidase was genetically modified by fusing it to an elastin-like polypeptide (ELP) [27]. In this work, catalase (CAT) was fused to ELP through genetic engineering technology. ELP-DAAO and ELP-CAT have been immobilized on carbon nanotubes (CNTs) separately. 
Elastin-like polypeptides undergo a sharp and reversible phase transition at a specific temperature [28]; thus, ELP-DAAO and ELP-CAT were purified through phase transition, which has been demonstrated to be an efficient and simple way to purify the enzymes. Oxidized multi-walled carbon nanotubes (O-MWNTs) were used to immobilize ELP-DAAO and ELP-CAT. ELP-DAAO/O-MWNTs and ELP-CAT/O-MWNTs sequentially catalyze the deamination of D-alanine and the decomposition of the evolved $\mathrm{H}_{2} \mathrm{O}_{2}$. In situ decomposing hydrogen peroxide can significantly reduce the deterioration of the enzymes and the inhibitory effect on the catalysis, facilitating the utilization of evolved molecular oxygen to re-oxidize the flavin adenine dinucleotide (FAD) factor of ELP-DAAO.

\section{Results and Discussion}

\subsection{FTIR analysis}

The FTIR spectra (the blue lines in Figure 1) are for the conjugates of ELP-DAAO/O-MWNTs and ELP-CAT/O-MWNTs. The bands at 1635, 1636, and $1638 \mathrm{~cm}^{-1}$ and 1546, 1541, and $1540 \mathrm{~cm}^{-1}$ are due to primary and secondary amines of the enzymes, respectively [29]. The bands at 3189, 3274, 3281, and $3290 \mathrm{~cm}^{-1}$ are ascribed to the hydroxyl groups of the enzymes. The FTIR spectra confirmed the immobilization of the enzymes on O-MWNTs.
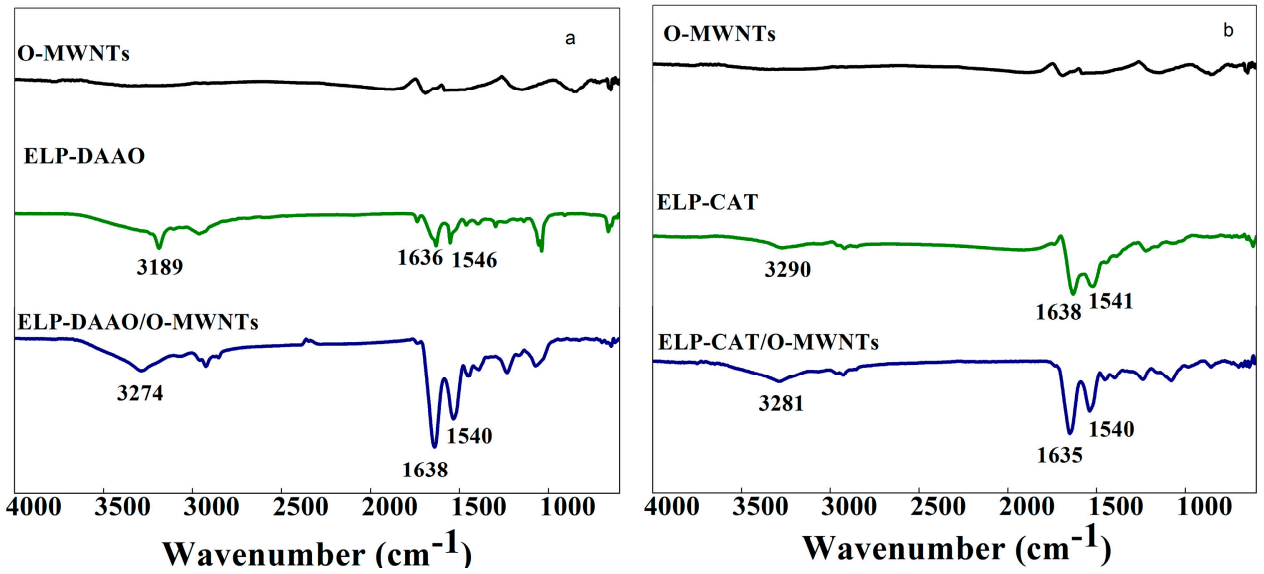

Figure 1. FTIR spectra of immobilized ELP-DAAO (a) and ELP-CAT (b) on oxidized multi-walled carbon nanotubes (O-MWNTs). ELP: Elastin-like polypeptide; CAT: Catalase; DAAO: D-amino acid oxidase.

\subsection{X-Ray Photoelectron Spectroscopy}

X-Ray Photoelectron Spectroscopy (XPS) has been demonstrated to be a powerful tool for the surface analysis of enzyme-immobilized carbon nanotubes [30]. Figure 2 shows the XPS spectra of the enzyme/O-MWNTs. Compared to that of O-MWNTs, the spectra of ELP-DAAO/O-MWNTs and ELP-CAT/O-MWNTs show an increase in the intensity of oxygen. This is attributed to the oxygen from the ELP-DAAO and ELP-CAT. Moreover, the nitrogen from the enzymes appeared in the spectra after enzyme immobilization. 


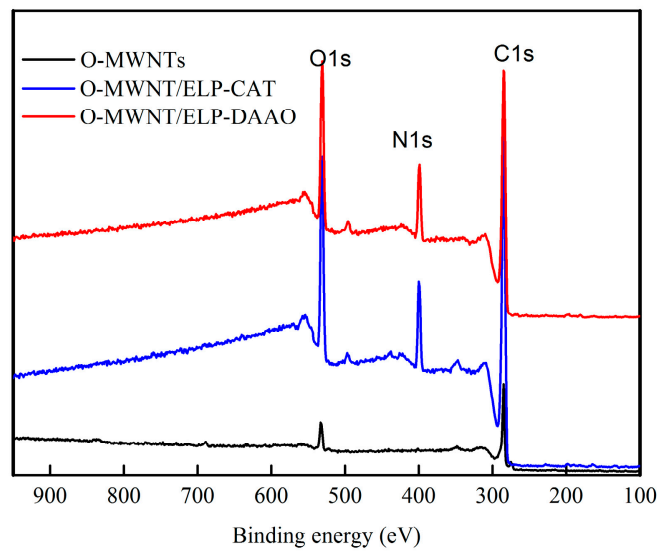

Figure 2. X-Ray Photoelectron Spectroscopy (XPS) spectra for the immobilized enzymes

\subsection{Raman Spectra Analysis}

Immobilization of the enzymes on O-MWNTs can be analyzed based on Raman spectra (Figure 3). The G-band is in the $1500-1600 \mathrm{~cm}^{-1}$ region [31], and the D-band is in the $1300-1400 \mathrm{~cm}^{-1}$ region. The strength of the D-band is affected by the amount of disordered graphite and the degree of disruption in the graphene sheet. The intensity ratios of D to G bands of ELP-DAAO/O-MWNTs and ELP-CAT/O-MWNTs are greater than those of O-MWNTs. This confirmed that during the immobilization of the enzymes, covalent reactions occurred between the $\mathrm{NH}_{2}$ - groups of the enzymes and the carboxyl groups of O-MWNTs.

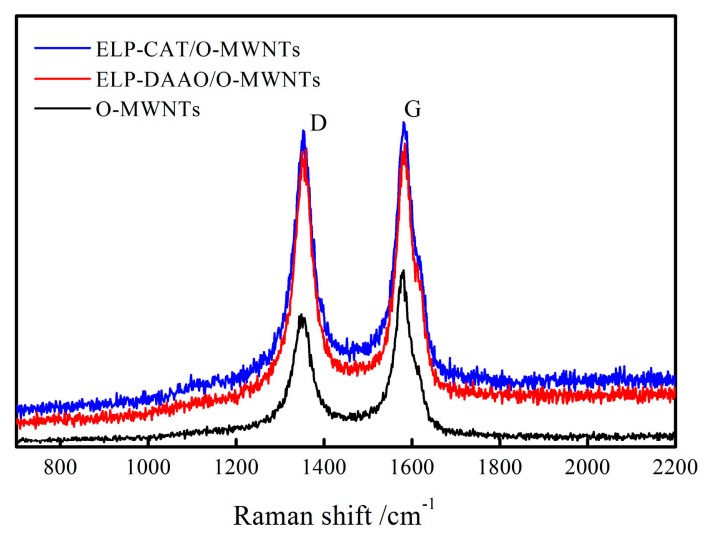

Figure 3. Raman spectra for the immobilized enzymes

\subsection{Circular Dichroism Spectra Analysis}

Circular Dichroism (CD) spectroscopy was used to analyze the influence of immobilization on the secondary structure of the enzymes. Figure 4 shows the CD spectra of ELP-DAAO, ELP-DAAO/O-MWNTs, ELP-CAT, and ELP-CAT/O-MWNTs. In the measurement of the CD spectra of the immobilized enzymes, the CD spectrum of O-MWNTs was recorded as a control. The blue lines are for the immobilized enzymes, and the black lines are for free enzymes. The blue lines are close to the black lines. Especially for the mean residue ellipticity at $222 \mathrm{~nm}$, which reflects the change of $\alpha$-helical content, the difference between the immobilized enzyme and the free enzyme is very small. It is indicated that the enzymes immobilized on O-MWNTs have retained the $\alpha$-helical content of the free enzymes. Figure S1 shows the near-UV CD spectra for the change of the tertiary structure of ELP-DAAO after immobilization. The black line for ELP-DAAO and the blue line for the 
immobilized ELP-DAAO are close to each other, indicating that the immobilization had a small effect on the tertiary structure.
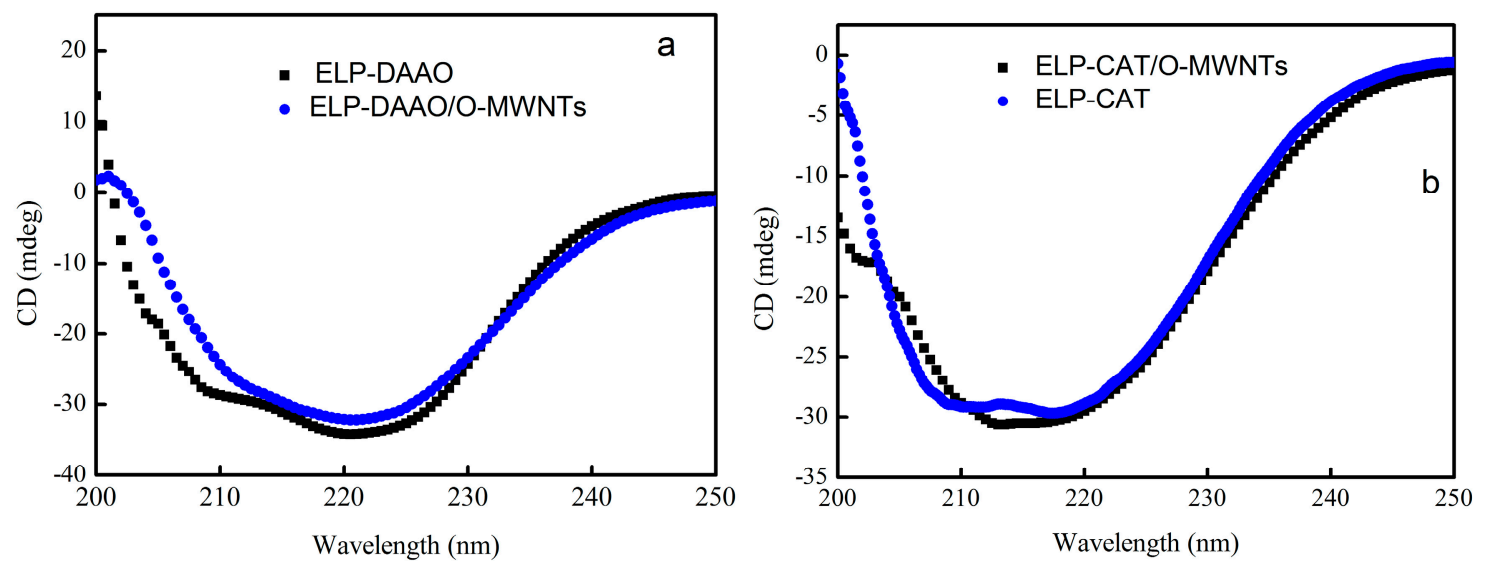

Figure 4. Circular Dichroism (CD) spectra for the immobilized ELP-DAAO (a) and ELP-CAT (b).

\subsection{Combination of Covalent and Non-Covalent Enzyme Immobilization}

The fusion protein ELP-DAAO has a hydrophobic ELP segment, while the DAAO segment is hydrophilic. In the immobilization of ELP-DAAO on MWNTs, ELP-DAAO was first covalently immobilized on MWNTs through amidation reactions between the $-\mathrm{NH}_{2}$ groups of DAAO segments and the carboxyl groups of oxidized MWNTs, as illustrated in Supplementary Scheme S1. Thus, close to the surface of MWNTs, the DAAO segments of ELP-DAAO contacted the surface of the MWNTs, and the ELP segments faced outward. The ELP segments are hydrophobic, and the self-assembly of the ELP segments led to further adsorption of ELP-DAAO on the MWNTs. So, the immobilization of ELP-DAAO included covalent attachment and non-covalent adsorption processes. The TEM image (Figure $5 b$ ) show that the immobilized ELP-DAAO exhibited aggregation as indicated by red arrows. It is implied that adsorption through the self-assembly of the ELP segments is a dominant process for the immobilization of ELP-DAAO. Most of the immobilized ELP-DAAO was immobilized through non-covalent interactions. The non-covalent interactions facilitated the preservation of the secondary structures of the immobilized ELP-DAAO. A similar immobilization process occurred for the immobilization of ELP-CAT. This is possibly the reason that the secondary structures of ELP-DAAO and ELP-CAT were preserved after immobilization, as indicated by Figure 4.

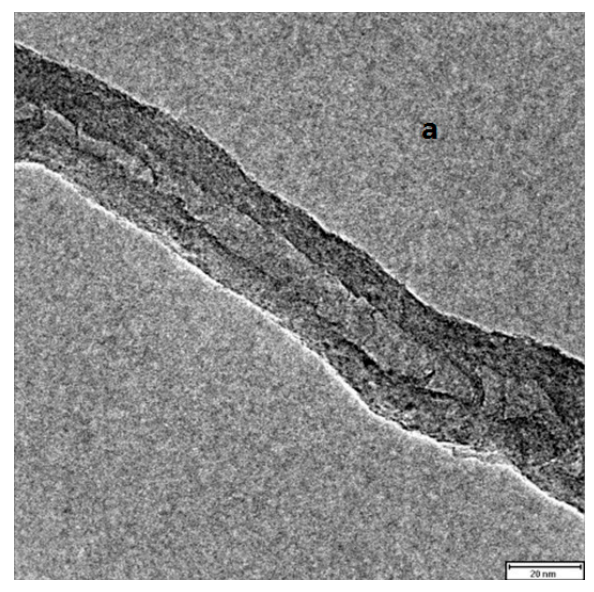

Figure 5. Cont. 


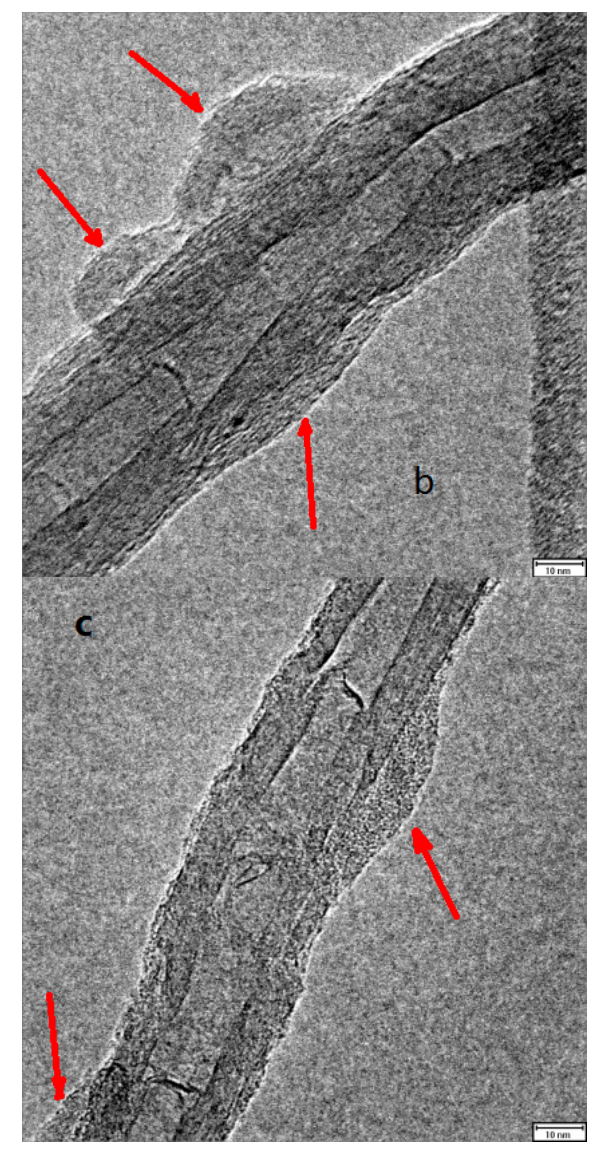

Figure 5. TEM images of Oxidized MWNTs (a); ELP-DAAO/O-MWNTs (b); ELP-CAT/ O-MWNTs (c). The red arrows indicate the immobilized enzymes.

\subsection{Enzymatic Catalysis}

The immobilized enzymes ELP-DAAO/O-MWNTs and ELP-CAT/O-MWNTs have been utilized to catalyze the oxidative deamination of D-alanine. $\mathrm{H}_{2} \mathrm{O}_{2}$ was the by-product and was evolved continuously. When the MWNT-supported enzymes were used together, the generated hydrogen peroxide of ELP-DAAO were able to be decomposed by ELP-CAT. Thus, the inhibition and deterioration effects of the hydrogen peroxide were significantly reduced, and molecular evolved oxygen could be utilized to re-oxidize the FAD factor of ELP-DAAO, which was reduced during the catalysis. Oxidizing the FAD factor is essential to maintaining the activity of ELP-DAAO. Two-enzyme systems with different weight ratios of ELP-CAT/O-MWNTs to ELP-ELP/O-MWNTs were investigated. Figure 6 shows the results, in which the specific activity ratio is defined as the ratio of the specific activity of the immobilized enzymes to the specific activity of ELP-DAAO $(0.21 \mathrm{U} / \mathrm{mg})$ [27]. Obviously, a larger specific activity ratio means a higher specific activity. When only using the immobilized ELP-DAAO (ELP-DAAO/O-MWNTs), the specific activity is slightly larger than that of free ELP-DAAO. The two-immobilized-enzyme systems exhibited significantly larger activities than the system with only immobilized ELP-DAAO. When the weight ratios were larger than 1:1, the two-enzyme systems exhibited a specific activity more than five times that of free enzyme, demonstrating the contribution of ELP-CAT/O-MWNTs to the enhanced specific activity. The results also demonstrated that it is not necessary to use weight ratios larger than 1:1, as the difference in the activity for different ratios is not significant. 


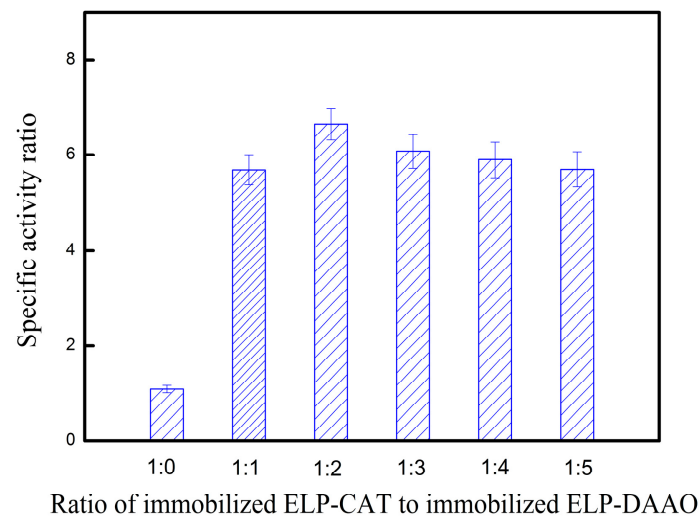

Figure 6. Specific activity ratios as a function of the ratio of immobilized ELP-CAT to immobilized ELP-DAAO.

The concentration of the immobilized ELP-DAAO was $0.3 \mathrm{mg} / \mathrm{mL}$. For the weight ratios 1:0, $1: 1,1: 2,1: 3,1: 4$, and 1:5, the overall immobilized enzyme concentrations were $0.3,0.6,0.9,1.2,1.5$, and $1.8 \mathrm{mg} / \mathrm{mL}$, respectively. The specific activity ratio is the ratio of the specific activity of two immobilized enzymes to the specific activity of ELP-DAAO.

\section{Experimental section}

\subsection{Materials}

Multi-walled carbon nanotubes (MWNTs) were purchased from Nanotech Port Co., Ltd. (Shenzhen, China), with a purity higher than 98\%. N-ethyl-N-(3-(dimethylamino)propyl) carbodiimide hydrochloride (EDC), (R,S)-1-Phenyl ethanol, 2-(N-morpholino) ethanesulfonic acid (MES), N-hydroxysuccinimide (NHS) were purchased from Sigma-Aldrich Chemical Co., China. All other reagents were purchased from Sinopharm Chemical Reagent Co., Ltd (Shanghai, China) or Sigma-Aldrich (Shanghai, China) and used without additional purification processes. Elastin-like polypeptide (ELP), modified D-Amino acid oxidase, and catalase were expressed and purified as described in our previous work [27]. The expression vector pET28a/(VPGXG) ${ }_{60}$-CAT in Escherichia coli was constructed. Table S1 lists the gene sequence of ELP. Figure S2 shows the construct schematically. Figures S3 and S4 show the SDS-PAGE analysis for the purified ELP-DAAO and ELP-CAT.

\subsection{Purification and Oxidation of MWNTs}

MWNTs were purified and oxidized according to the description in [32]. MWNTs were purified through refluxing in $\mathrm{HNO}_{3}(2.6 \mathrm{M})$ for $12 \mathrm{~h}$ at $65^{\circ} \mathrm{C}$. By filtering through a $0.45 \mu \mathrm{m}$ polycarbonate membrane, the MWNTs suspension was rinsed with distilled water. MWNTs were dried at $70{ }^{\circ} \mathrm{C}$ under vacuum. The dried MWNTs were added to a solution of $\mathrm{H}_{2} \mathrm{SO}_{4}: \mathrm{HNO}_{3}$ (3:1) and incubated for 3 hours. The oxidized MWNTs were rinsed with distilled water by filtering through a $0.45 \mu \mathrm{m}$ polycarbonate membrane. The oxidized MWNTs was dried at $70^{\circ} \mathrm{C}$ under vacuum.

\subsection{Enzyme Immobilization}

The immobilization of ELP-DAAO on O-MWNTs was carried out as described in previous work [33]. $100 \mathrm{mg}$ of O-MWNTs was dispersed in $100 \mathrm{~mL}$ of MES buffer (pH 6.2, $50 \mathrm{mM}$ ). The mixture was then added to a solution of NHS in MES buffer and sonicated; after $10 \mathrm{~min}$, EDC (10 mmol/L) was added. The mixture was shaken at $150 \mathrm{rpm}$ for $1 \mathrm{~h}$. Thus O-MWNTs were activated and were rinsed with MES buffer to remove excess EDC and NHS by filtering through a polycarbonate membrane. The obtained O-MWNTs were transferred to the ELP-DAAO solutions $(4.5 \mathrm{mg} / \mathrm{mL})$ and sonicated for half a minute to redisperse O-MWNTs. The mixtures were then shaken at $200 \mathrm{rpm}$ at $4{ }^{\circ} \mathrm{C}$ for 
$10 \mathrm{~h}$. The mixtures were centrifuged at $4{ }^{\circ} \mathrm{C}$ for $15 \mathrm{~min}$ at $6000 \mathrm{~g}$. Six washes were carried out by adding fresh buffer each time to remove unbound ELP-DAAO. Using the micro bicinchoninic acid (BCA) assay, the concentrations of ELP-DAAO in the solutions were determined, as described in our previous work [34]. By measuring the enzyme ELP-DAAO in the original ELP-DAAO solutions, supernatants, and washing solutions, the amount of ELP-DAAO immobilized on the O-MWNTs was determined. Triplicate measurements were performed. The amount of immobilized ELP-DAAO was finally determined to be $0.26 \pm 0.01 \mathrm{mg}$ ELP-DAAO/mg O-MWNTs. A similar approach has been used to immobilize ELP-CAT on O-MWNTs, and the amount of ELP-CAT immobilized was determined to be $0.31 \pm 0.01 \mathrm{mg}$ ELP-CAT/mg O-MWNTs

\subsection{Measurement}

Circular dichroism (CD) spectroscopy was used to monitor the change of the secondary structure of the enzymes after immobilization. CD spectra were measured on a JASCO J-810 CD instrument. The bandwidth was $0.5 \mathrm{~nm}$ and the scan speed was $50 \mathrm{~nm} / \mathrm{min}$. Cell length was $1 \mathrm{~cm}$. The enzyme concentration was $47 \mu \mathrm{g} / \mathrm{ml}$, and the measurements were performed at $25^{\circ} \mathrm{C}$. The CD spectrum of $\mathrm{O}-\mathrm{MWNTs}$ was used as control. The spectra were averaged by repeating the scan five times.

XPS spectra were measured using an X-ray photoelectron spectrometer (Thermo VG ESCALAB250, Thermo Fisher Scientific, Shanghai, China). The measurement was carried out at a pressure of $2 \times 10^{-9} \mathrm{~Pa}$. Mg Ka X-ray was used as the excitation source. Raman spectra were measured on a Renishaw InVia equipment. UV-vis spectra were measured on a Shimadzu spectrophotometer (UV2550-PC).

Infrared spectra were measured using a Fourier transform infrared (FTIR) spectrometer (Bruker TENSOR 27). A horizontal temperature-controlled attenuated total reflectance (ATR) with ZnSe Crystal was used. A liquid-nitrogen-cooled mercury-cadmium-telluride detector was used to collect 128 scans per spectrum; the resolution was $2 \mathrm{~cm}^{-1}$. The ATR element spectrum was used as the background. Ultrapure nitrogen gas was introduced to purge water vapor.

\subsection{Enzyme Assay and Analyses}

ELP-DAAO catalyzed the oxidative deamination of D-alanine, and $\mathrm{H}_{2} \mathrm{O}_{2}$ was evolved continuously. The enzyme activity was assayed at $30^{\circ} \mathrm{C}$. PBS buffer $(50 \mathrm{mM}, \mathrm{pH} 8.0)$ was used as the reaction media. Different ratios of immobilized ELP-CAT to immobilized ELP-DAAO were used for the enzymatic catalysis. The concentration of the immobilized ELP-DAAO was $0.3 \mathrm{mg} / \mathrm{mL}$. The D-alanine concentrations were determined by HPLC (Shimadzu 15 LC-10A, Shimadzu, Shanghai, China) with a C18 column (Diamonsil C18 $250 \times 4.6 \mathrm{~mm}, 5 \mu \mathrm{m})$. The mobile phase was PBS $(0.05 \mathrm{M}$ and $\mathrm{pH} 2.5) /$ methanol ( $95: 5$ by volume) at a flow rate of $0.8 \mathrm{~mL} / \mathrm{min}$, the injection was $20 \mu \mathrm{L}$.

\section{Conclusions}

Genetically-modified D-amino acid oxidase (ELP-DAAO) and catalase (ELP-CAT) have been separately immobilized on oxidized multi-walled carbon nanotubes (O-MWNTs). ELP-DAAO and ELP-CAT have the hydrophilic segments DAAO and CAT, respectively. The ELP segments are hydrophobic. The enzymes were first covalently attached to the surface of O-MWNTs through the reactions between the amino groups of the hydrophilic segments and the carboxyl groups of O-MWNTs. Subsequent immobilization of the enzymes was accomplished by adsorption induced by the self-assembly of the ELP segments. The secondary structures of the enzymes were preserved after immobilization. The two immobilized enzymes were used to catalyze the oxidative deamination of D-alanine. The generated hydrogen peroxide of DAAO can be decomposed by ELP-CAT. Thus, the inhibition and deterioration effects of the hydrogen peroxide were significantly reduced, and molecular evolved oxygen can be utilized to re-oxidize the FAD factor of ELP-DAAO, which was reduced during catalysis. Oxidizing the FAD factor is essential to maintaining the activity of ELP-DAAO. When the weight ratio of ELP-DAAO/O-MWNTs to ELP-CAT/O-MWNTs was larger 
than 1:1, the two-enzyme systems exhibited specific activities more than five times that of free enzyme ELP-DAAO, demonstrating the contribution of ELP-CAT/O-MWNTs to the enhanced specific activity.

Supplementary Materials: The following are available online at www.mdpi.com/2073-4344/6/5/66/s1: Table S1: Elastin-like polypeptide (ELP) monomer, Scheme S1: Schematic presentation for covalent immobilization of enzymes on carbon nanotubes (CNTs). EDC: $N$-ethyl- $N$-(3-(dimethylamino)propyl) carbodiimide hydrochloride; NHS: N-hydroxysuccinimide, Figure S1: Near-UV circular dichroism (CD) spectra of ELP-DAAO (black) and immobilized ELP-DAAO (blue). The near-UV CD spectra were measured at 250-320 nm, with protein concentrations of $1 \mathrm{mg} / \mathrm{mL}$. DAAO: D-Amino Acid Oxidase; O-MWNTs: Oxidized Multi-Walled Carbon Nanotubes, Figure S2: Schematic presentation of constructed vector for ELP-CAT. CAT: Catalase, Figure S3: Analysis of purified ELP-DAAO fusion protein by SDS-PAGE. Lane M: molecular mass marker (KDa); Lane 1 is for the supernatants from the third round of inverse transition cycling; Lane 2 is for total proteins, Figure S4: Analysis of purified ELP-CAT fusion protein by SDS-PAGE. Lane M: molecular mass marker (KDa); Lane 1 is for the supernatants from the third round of inverse transition cycling.

Acknowledgments: This work was supported by the National Science Foundation of China $(21376021,21576018)$.

Author Contributions: Wei Feng and Peijun Ji provided the idea and design for the study; Rong Li and Jian Sun performed the experiments; Yaqi Fu, Kun Du and Mengsha Cai analyzed the data; Rong Li drafted the manuscript; Wei Feng and Peijun Ji revised it.

Conflicts of Interest: The authors declare no conflict of interest.

\section{References}

1. Pollegioni, L.; Molla, G. New biotech applications from evolved D-amino acid oxidases. Trends Biotechnol. 2011, 29, 276-283. [CrossRef] [PubMed]

2. Takahashi, S.; Furukawara, M.; Omae, K.; Tadokoro, N.; Saito, Y.; Abe, K.; Kera, Y. A highly stable D-amino acid oxidase of the thermophilic bacterium rubrobacter xylanophilus. Appl. Environ. Microbiol. 2014, 80, 7219-7229. [CrossRef] [PubMed]

3. Deng, S.; Su, E.; Ma, X.; Yang, S.; Wei, D. High-level soluble and functional expression of trigonopsis variabilis D-amino acid oxidase in escherichia coli. Bioprocess Biosyst. Eng. 2014, 37, 1517-1526. [CrossRef] [PubMed]

4. Yasukawa, K.; Nakano, S.; Asano, Y. Tailoring D-amino acid oxidase from the pig kidney to R-stereoselective amine oxidase and its use in the deracemization of $\alpha$-methylbenzylamine. Angew. Chem. Int. Ed. 2014, 53, 4428-4431. [CrossRef] [PubMed]

5. Pilone, M.S.; Buto, S.; Pollegioni, L. A process for bioconversion of cephalosporin C by rhodotorula gracilis D-amino acid oxidase. Biotechnol. Lett. 1995, 17, 199-204. [CrossRef]

6. Hernandez, K.; Berenguer-Murcia, A.; Rodrigues, R.C.; Fernandez-Lafuente, R. Hydrogen peroxide in biocatalysis. A dangerous liaison. Curr. Org. Chem. 2012, 16, 2652-2672. [CrossRef]

7. Upadhya, R.; Nagajyothi, Bhat S.G. Stabilization of D-amino acid oxidase and catalase in permeabilized rhodotorula graciliscells and its application for the preparation of a-ketoacids. Biotechnol. Bioeng. 2000, 68, 430-436. [CrossRef]

8. Fernandez-Lafuente, R.; Rodriguez, V.; Guisan, J.M. The coimmobilization of D-amino acid oxidase and catalase enables the quantitative transformation of D-amino acids (D-phenylalanine) into $\alpha$-keto acids (phenylpyruvic acid). Enzyme Microb. Technol. 1998, 23, 28-33. [CrossRef]

9. Trost, E.M.; Fischer, L. Minimization of by-product formation during D-amino acid oxidase catalyzed racemate resolution of D/L-amino acids. J. Mol. Catal. B: Enzym. 2002, 19-20, 189-195. [CrossRef]

10. Li, B.; Zhang, Z. Chemiluminescence flow biosensor for determination of total D-amino acid in serum with immobilized reagents. Sens. Actuators B 2000, 69, 70-74. [CrossRef]

11. Domínguez, R.; Serra, B.; Reviejo, A.J.; Pingarrón, J.M. Chiral analysis of amino acids using electrochemical composite bienzyme biosensors. Anal. Biochem. 2001, 298, 275-282. [CrossRef] [PubMed]

12. Pernot, P.; Mothet, J.P. Characterization of a yeast D-amino acid oxidase microbiosensor for D-serine detection in the central nervous system. Anal. Chem. 2008, 80, 1589-1597. [CrossRef] [PubMed]

13. Inaba, Y.; Mizukami, K.; Hamada-Sato, N.; Kobayashi, T.; Imada, C.; Watanabe, E. Development of D-alanine sensor for the monitoring of a fermentation using the improved selectivity by the combination of D-amino acid oxidase and pyruvate oxidase. Biosens. Bioelectron. 2003, 19, 423-431. [CrossRef]

14. Rosini, E.; Molla, G.; Rossetti, C.; Pilone, M.S.; Pollegioni, L.; Sacchi, S. A biosensor for all D-amino acids using evolved D-amino acid oxidase. J. Biotechnol. 2008, 135, 377-384. [CrossRef] [PubMed]

15. Mora, M.F.; Giacomelli, C.E.; Garcia, C.D. Interaction of D-amino acid oxidase with carbon nanotubes: implications in the design of biosensors. Anal. Chem. 2009, 81, 1016-1022. [CrossRef] [PubMed] 
16. Koszelewski, D.; Pressnitz, D.; Clay, D.; Kroutil, W. Deracemization of mexiletine biocatalyzed by $\omega$-transaminases. Org. Lett. 2009, 11, 4810-4812. [CrossRef] [PubMed]

17. Seo, Y.M.; Mathew, S.; Bea, H.S.; Khang, T.H.; Lee, S.H.; Kim, B.G.; Yun, H. Deracemization of unnatural amino acid: homoalanine using D-amino acid oxidase and ù-transaminase. Org. Biomol. Chem. 2012, 10, 2482-2485. [CrossRef] [PubMed]

18. Chen, Y.J.; Goldberg, S.L.; Hanson, R.L.; Parker, W.L.; Gill, I.; Tully, T.P.; Montana, M.A.; Goswami, A.; Patel, R.N. Enzymatic preparation of an (s)-amino acid from a racemic amino acid. Org. Process Res. Dev. 2011, 15, 241-248. [CrossRef]

19. Parkin, K.; Hultin, H.O. Immobilization and characterization of D-amino acid oxidase. Biotechnol. Bioeng. 1979, 21, 939-953. [CrossRef] [PubMed]

20. López-Gallego, F.; Betancor, L.; Mateo, C.; Hidalgo, A.; Alonso-Morales, N.; Dellamora-Ortiz, G.; Guisán, J.M.; Fernández-Lafuente, R. Enzyme stabilization by glutaraldehyde crosslinking of adsorbed proteins on aminated supports. J. Biotechnol. 2005, 119, 70-75. [CrossRef] [PubMed]

21. Zhao, Y.; Zhu, Y.; Fu, J. Manageable cytotoxicity of nanocapsules immobilizing D-amino acid oxidase via exogenous administration of nontoxic prodrug. Appl. Surf. Sci. 2014, 293, 109-115. [CrossRef]

22. Yoshimoto, M.; Yamasaki, M.; Okamoto, M.; Umakoshi, H.; Kuboi, R. Oligolamellar vesicles for covalent immobilization and stabilization of D-amino acid oxidase. Enzyme Microb. Technol. 2013, 52, 13-19. [CrossRef] [PubMed]

23. Mujawar, S.K.; Kotha, A.; Rajan, C.R.; Ponrathnam, S.; Shewale, J.G. Development of tailor-made glycidyl methacrylate-divinyl benzene copolymer for immobilization of D-amino acid oxidase from aspergillus species strain 020 and its application in the bioconversion of cephalosporin C. J. Biotechnol. 1999, 75, 11-22. [CrossRef]

24. Mu, X.; Qiao, J.; Qi, L.; Liu, Y.; Ma, H. Construction of a D-amino acid oxidase reactor based on magnetic nanoparticles modified by a reactive polymer and its application in screening enzyme inhibitors. ACS Appl. Mater. Interfaces 2014, 6, 12979-12987. [CrossRef] [PubMed]

25. Bolivar, J.M.; Nidetzky, B. Oriented and selective enzyme immobilization on functionalized silica carrier using the cationic binding module zbasic2: Design of a heterogeneous D-amino acid oxidase catalyst on porous glass. Biotechnol. Bioeng. 2012, 109, 1490-1498. [CrossRef] [PubMed]

26. Wong, K.S.; Fong, W.P.; Tsang, P. Entrapment of a trigonopsis variabilis D-amino acid oxidase variant F54Y for oxidative deamination of cephalosporin C. Eng. Life Sci. 2011, 11, 491-495. [CrossRef]

27. Du, K.; Sun, J.; Song, X.; Song, C.; Feng, W. Enhancement of the solubility and stability of D-amino acid oxidase by fusion to an elastin like polypeptide. J. Biotechnol. 2015, 212, 50-55.

28. Meyer, D.E.; Chilkoti, A. Genetically encoded synthesis of protein-based polymers with precisely specified molecular weight and sequence by recursive directional ligation: examples from the elastin-like polypeptide system. Biomacromolecules 2002, 3, 357-367. [CrossRef] [PubMed]

29. Du, K.; Sun, J.; Song, X.Q.; Chen, H.M.; Feng, W.; Ji, P.J. Interaction of ionic liquid [bmin][CF3SO3] with lysozyme investigated by two-dimensional fourier transform infrared spectroscopy. ACS Sustain. Chem. Eng. 2014, 2, 1420-1428. [CrossRef]

30. Sun, J.; Du, K.; Song, X.; Gao, Q.; Ma, J.; Ji, P.; Feng, W. Specific Immobilization of D-amino Acid Oxidase Mimicking Multi-enzyme Catalysis. Green Chem. 2015, 17, 4465-4472. [CrossRef]

31. Sinani, V.A.; Gheith, M.K.; Yaroslavov, A.A.; Rakhnyanskaya, A.A.; Sun, K.; Mamedov, A.A.; Wicksted, J.P.; Kotov, N.A. Aqueous dispersions of single-wall and multiwall carbon nanotubes with designed amphiphilic polycations. J. Am. Chem. Soc. 2005, 127, 3463-3472. [CrossRef] [PubMed]

32. Liu, J.; Rinzler, A.G.; Dai, H.; Hafner, J.H.; Bradley, R.K.; Boul, P.J.; Lu, A.; Iverson, T.; Shelimov, K.; Huffman, C.B. Fullerene pipes. Science 1998, 280, 1253-1256. [CrossRef] [PubMed]

33. Ji, P.J.; Tan, H.S.; Xu, X.; Feng, W. Lipase covalently attached to multiwalled carbon nanotubes as an efficient catalyst in organic solvent. AIChE J. 2010, 56, 3005-3011. [CrossRef]

34. Sun, J.; Du, K.; Fu, L.; Gao, J.; Zhang, H.Y.; Feng, W.; Ji, P. Sodium hexadecyl sulfate as an interfacial substance adjusting the adsorption of a protein on carbon nanotubes. ACS Appl. Mater. Interfaces 2014, 6, 15132-15139. [CrossRef] [PubMed]

(C) 2016 by the authors; licensee MDPI, Basel, Switzerland. This article is an open access article distributed under the terms and conditions of the Creative Commons Attribution (CC-BY) license (http://creativecommons.org/licenses/by/4.0/). 